\title{
EMHD radiating fluid flow along a vertical Riga plate with suction in a rotating system
}

\author{
Sheela Khatun ${ }^{1} \cdot$ Muhammad Minarul Islam ${ }^{1} \cdot$ Md. Tusher Mollah ${ }^{2,3} \cdot$ Saykat Poddar $^{1}$ (D) Md. Mahmud Alam ${ }^{4}$
}

Received: 8 July 2020 / Accepted: 25 February 2021 / Published online: 12 March 2021

(C) The Author(s) 2021 OPEN

\begin{abstract}
This study is performed on the numerical investigation of electro-magnetohydrodynamic (EMHD) radiating fluid flow nature along an infinitely long vertical Riga plate with suction in a rotating system. The prevailing equations are generated from the Navier-Stokes' and energy equations. A uniform suction velocity is introduced to control the flow. The prevailing boundary layer $(\mathrm{BL})$ equations are the stuff to delineate the mechanical features of the flowing nature along with the electromagnetic device (Riga plate). Accordingly, the use of usual transformations on the equations transformed those into a coupled dimensionless system of non-linear partial differential equations (PDEs). After conversion, the elucidation of the set of equations is conducted numerically by an explicit finite difference method (FDM). The criteria for stable and converging solutions are constructed to find restrictions on various non-dimensional parameters. The retrieved restrictions are $P_{r} \geq 0.19, R_{d} \geq 0.1, S \geq 1, E_{c}=0.01$ and $0<R \leq 0.1$. Furthermore, sensitivity tests on mesh and time as well as comparison within the literature have been demonstrated in graphical and tabular form. Finally, the important findings of the non-dimensional parameters influences have been portrayed in graphical manner by using the MATLAB R2015a tool. A substantial uprise is noted for both the velocities (secondary and primary) under the rising actions of the modified Hartmann number, whereas the suction parameter suppresses both the velocities.
\end{abstract}

Keywords Riga Plate - Suction · FDM - Thermal Radiation

$\begin{array}{ll}\begin{array}{l}\text { Abbreviations } \\ u, w\end{array} & \begin{array}{l}\text { Cartesian primary and secondary velocity } \\ \text { components }\end{array} \\ T_{w} & \quad \text { Temperature adjacent to the plate } \\ T_{\infty} & \text { Temperature in the free stream region } \\ M_{0} & \text { Magnetization of the permanent magnet } \\ c_{p} & \text { Specific heat at constant pressure } \\ J_{0} & \text { Current density in the electrodes } \\ a & \text { Uniform width of the magnets and electrodes } \\ U, W & \text { Dimensionless primary velocity and secondary } \\ \theta & \text { velocity components } \\ \tau & \text { Dimensionless temperature } \\ Q_{r} & \text { Dimensionless time } \\ & \text { Radiative heat flux }\end{array}$

$k^{*} \quad$ Mean absorption coefficient

$Z \quad$ Modified Hartman number

$R \quad$ Rotational parameter

$P_{r} \quad$ Prandtl number

$R_{d} \quad$ Radiation parameter

$E_{c} \quad$ Eckert number

$S$ Suction parameter

$\mathrm{Nu}_{L} \quad$ Local Nusselt number

Greek symbols

$v \quad$ Kinematic viscosity

$\sigma \quad$ Electrical conductivity

$\rho \quad$ Density of the fluid

$\beta_{C} \quad$ Mass expansion coefficient

$\kappa \quad$ Thermal conductivity

$\triangle$ Saykat Poddar, saykat.sp@gmail.com | 'Department of Mathematics, Faculty of Science, Bangabandhu Sheikh Mujibur Rahman Science and Technology University, Gopalganj 8100, Bangladesh. ${ }^{2}$ Department of Mechanical Engineering, Technical University of Denmark, Kgs. Lyngby 2800, Denmark. ${ }^{3}$ Department of Mathematics, European University of Bangladesh, Dhaka 1216, Bangladesh. ${ }^{4}$ Mathematics Discipline, Science, Engineering and Technology School, Khulna University, Khulna 9208, Bangladesh. 


\section{$\sigma^{*} \quad$ Stefan-Boltzman constant \\ $\tau_{L x} \quad$ Local primary shear stress \\ $\tau_{L z} \quad$ Local secondary shear stress}

\section{Subscripts}

w Condition at plate

$\infty \quad$ Condition for free stream flow

\section{Introduction}

An electromagnetic actuator that consists of the aggregation of adjusted magnets along with the spanwise arranged layout of electrodes with alternation mounting on a flat surface is indicated as a Riga plate. This actuator is responsible for the generation of exponentially decreasing Lorentz force within the BL. This device has been employed in the reduction of pressure drag and friction with the aid of the prevention of the separation in the boundary layer $(\mathrm{BL})$ and to abate the generation of turbulence criteria [1]. Magnetohydrodynamics (MHD) flows with the Riga surface exert a workable role in miscellaneous engineering actions like in MHD generators, flow meters, and thermal nuclear reactors, etc. The flows with the consideration of the Riga plate have comprehensive usages in chemical engineering, civil engineering, mechanical engineering, etc. Riga plate can be efficiently used in biomedical sciences with nanoparticles based fluid flow.

The flow concerning Newtonian fluid under the influence of the Riga plate generates the "Grinberg term" that produces the electromagnetic parameter naming as the modified Hartmann number [2]. For aiding flow, this parameter possesses positive values, and opposing flow possesses negative values [3]. Micro-electromagnetic systems are growing faster with rapidly renewed applications of flow mechanisms concerning the Riga plate. Biomechanically, for developing smart lubrication, the flow concerning the Riga plate is significant.

Electrically conducting fluids in MHD flows have captivated many investigators for their medley applications in engineering assignments, see Refs. [4-12]. But unfortunately, a large electrical conductivity is not often contained by all the available fluids. Taking this deficiency into consideration, the Riga plate was foremost introduced by Gailitis and Lielausic [13] as a flow monitoring device to produce parallel Lorentz force to the wall. The decision by their investigation concluded that the electromagnetic forces can govern the fluid with electric conduction to compensate for the lack of momentum in the BL. The study incorporating the inspection of the fluctuating nonNewtonian flow nature of a Maxwell fluid with changeable suction velocity was performed by Wang and Hayat [14]. They have noted a negative BL flow criteria with the large amplitude of oscillation of the free stream flow, albeit the nature of the external flow is always forward-flowing. Deswita et al. [15] established similarity solutions for BL laminar flow with regard to a horizontal plate of permeable nature. The consideration of Riga plate to quest Blasius and Sakiadis flow was researched by Pantokratoras [16]. Two wielded flows with the shifting Lorentz points in the positive and negative direction along the Riga plate have been inspected by Magyari and Pantokratoras [17]. Vadher et al. [18] took an endeavor to observe the MHD squeeze films through a conducting lubricant bounded by two conical porous surfaces. Abbas et al. [19] established numerical reckoning of the entropy generation process on nanoparticle flow aiding a horizontally placed Riga plate. They examined the functioning of the profile of entropy as an escalating case for all the possible combinations of parameters. The effect of buoyancy by shooting procedure on nanofluid flow with the involvement of the Riga plate adopting convective heating was developed by Ahmad et al. [20]. Thermal radiation effect on MHD nanofluid flow dealing with no-slip setting past a Riga plate was depicted by Bhatti et al. [21]. Hayat et al. [22] inquired about the nanofluidic BL flow over the Riga plate of varying thickness by addressing the workable convective boundary conditions. Among many geometries of flow regarding the Riga plate, the flow wielding the inner zone of two Riga plates has created a remark for the number of applications. Paying heed to this context, The study on the observation of carbon-water nanofluidic squeezed flow between Riga plates by involving the radiation effects was presented by Ahmed et al. [23]. In the same year, Hayat et al. [24] observed the impact of the Riga plate involving in the EMHD flow of radiating and squeezing nature by addressing chemical reaction and convective conditions. Further, Hayat et al. [25] conducted a numerical study on EMHD squeezing flow with the rotation of carbon-water-kerosene oil nanofluid past through two Riga plates which are stretchable. lqbal et al. [26] reckoned the statistics of numerical elucidation on the transport of nanofluid concerning gyrotactic microorganisms drowned in water through the Riga plate with varying thickness and bio-convection. Under the involvement of Nield convective boundary conditions and flow activation energy, a research was executed by Khan et al. [27] on the flow analysis of thixotropic nano liquid over the Riga surface by aiming a biotechnological model. lqbal et al. [28] considered the Keller box scheme to investigate the dissipative and radiating effects on nanofluidic flow nature flowing through Riga surface under the property of erratic thickness. They reported an interesting fact that the transportation of heat flux rate is physically inverse to the mass flux rate for the radiational effect. An analytical approach on the third-grade flow of nanofluids adopting

\section{SN Applied Sciences}


the condition of zero mass flux for the nanoparticles past a Riga plate by employing the Cattaneo-Christov model was performed by Naseem et al. [29]. Rasool and Zhang [30] considered the HAM scheme to count the influences of convective boundary settings along with a chemical reaction on the Powell-Eyring type nanofluidic flow concerning Riga plate. Daniel et al. [31] considered the flow of nanofluid with reaction phenomena and electric field impacts under the employment of a nonlinear surface.

Overall, it is understood that thermal radiation is a key factor in analyzing different flow geometries for recent decades. This fact motivates the present study to deal with a radiating flow for the operational and fascinating Riga plate. Shafiq et al. [32] imposed a homotopy analytical technique to explore the Marangoni BL flow with radiation of carbon nanotubes along a Riga plate. Krishnamurthy et al. [33] worked out the chemical reaction effect of $\mathrm{BL}$ slip flow of radiating nanoparticle fluid along a stretching sheet of nonlinear type.

Prasannakumara et al. [34] accomplished the reckoning of the MHD flow problem emphasizing the dusty fluid containing double phase with the aid of convective boundary conditions and quadratic temperature at the surface. The phase velocity for particle was pointed lesser than the phase velocity for fluid simultaneously, the phase temperature for the dust was prescribed lesser than the phase temperature of the fluid. Shamshuddin et al. [35] paid their attention to analyze the Squeezing MHD flow by characterizing joule heating phenomena along with the heat flux structure of the Cattaneo-Christov type. The targetted purpose was the systematic improvement of the biomechanical smart lubrication. Furthermore, Heat flux of non-Fourier type has been characterized by Shamshuddin and Satya Narayana [36] with the relaxation of thermal behavior in the squeezing MHD flow. To mathematically inspect the squeeze films that are affected by magnetic force, the extensively used methodologies are mainly MHD viscous type. Nasir et al. [37] explored the numerical findings on the flow along a Riga plate of stretching/shrinking nature, where they considered dual solutions for the plate types. By their substantial inquiry, the upper branch of the solution was mentioned as a stable type while the lower branch wasn't. Ramesh et al. [38] researched Maxwell nanofluidic flow under MHD phenomena by the incorporation of heat source/sink. Due to the involvement of nano liquid, they observed an increment in velocity for the Maxwell parameter which denies the regular tendency of pull downing velocity by Maxwell parameter (without nano liquid).

The EMHD flow of conducting fluid for the permeable Riga surface is worthy of dealing with wall suction or injection, some investigations are [39-42]. Substantial studies on the magnetohydrodynamic flow of rotating fluid and/ or system rotation along with the preparation and applications of radiative heat flux have been executed by [43-47].

All the researches that have been surveyed above, clearly reflect that the flow maintaining device (Riga plate) is capturing the interests of researchers rapidly to quest the different causation of flow nature. However, to the best of the authors' knowing, no endeavor has yet been created to deal with the investigation of explicit FDM solution on the unsteadiness nature of viscous and incompressible flow induced by the vertical Riga plate of infinite length by considering the MHD phenomena with system rotation, thermal radiation, and suction. Mostly, the research endeavors that have been so far mentioned are constructed to deal with the flow that occurred by an external free stream or plate's motion however, the motivation of the present article is to observe the flow induced by the flow controlling device (Riga Plate) itself. Hence, to enhance the weighing of the literature in the authors' sense, a numerical and mathematical model is proposed here to understand the above-mentioned flow phenomena. The set of prevailing equations have been discretized to solve numerically. The numerical procedure for the current study is an explicit FDM (Eva et al. [48]). Outlining structures are; Sect. 2 explains the considered model with the mathematical representation. Section 3 presents the expressions for Nusselt number and shear stress. The numerical approach and its stability criteria are discussed in Sect. 4 and Sect. 5 respectively. Section 6 discusses the results in five subsections-Mesh Sensitivity, Time Sensitivity, Validation Test (Comparison), Effects of Affined Parameters, and Overall Qualitative Comparison. The salient marks of the results have been portrayed graphically and depicted in words.

\section{Model establishment and analysis}

An unsteady viscous, incompressible, and radiating fluid flow in a rotating system along a vertical Riga plate of infinite length has been considered under the action of Lorentz force due to the MHD phenomena. The repercussion of suction velocity is also considered by the action of the permeable Riga plate [39]. The Riga plate is assumed as an infinitely long surface that is erected at $y=0$ and holding the $x$-axis in the vertical position as configured in Fig. 1. Wielding of the fluid occurs through the vertical plate under the influence of Lorentz force that is generated by the flow monitoring device itself, and the Grinberg term is taken place into the mathematical scheme. The uniform magnetic field vector and the intensity of the electric field are organized in a parallel direction to the alignment. Assume, the plate surface temperature is $T_{w}$, while the external temperature of the $\mathrm{BL}$ region is $T_{\infty}$; to be more 


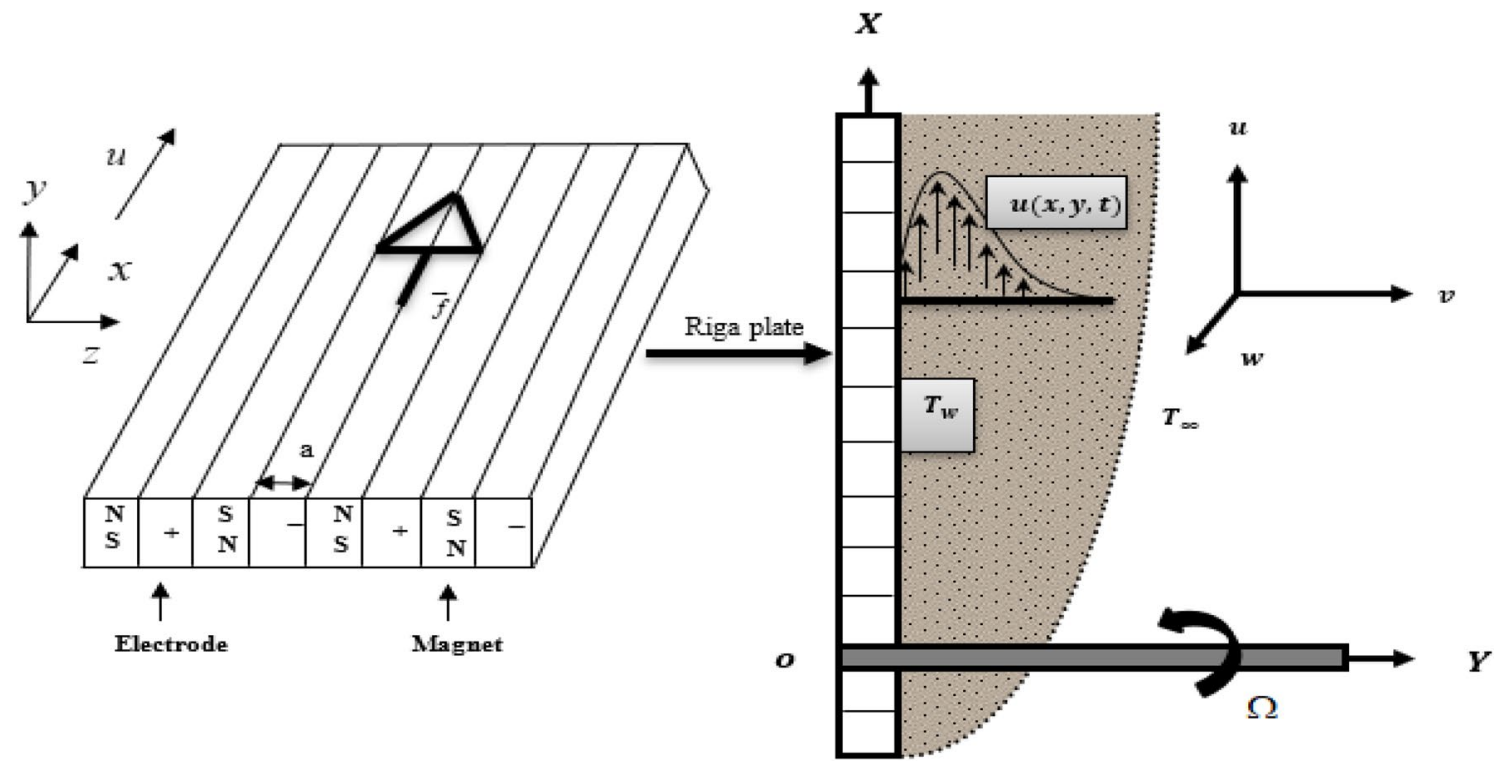

Fig. 1 The physical model and coordinates of the schematic problem

exact, $T_{w}>T_{\infty}$. Ineffective edge-effects can be deemed for the Riga plate and the imposed electric as well as magnetic fields that have elements particularly in $y$ and $z$ directions. As per the consideration of uniform suction, $\frac{\partial u}{\partial x}=0$, and the continuity equation $\frac{\partial u}{\partial x}+\frac{\partial v}{\partial y}=0$ generates $\frac{\partial x}{\partial y}=0$, which is taken as $v=-V_{0}$ (constant), see Refs. $[49,50]$.

Under the explications of the above-narrated assumptions, the prevailing $B L$ equations (see, $[12,21]$ ) related to the rotating frame by the operation of $\mathrm{BL}$ approximations are noted as:

\section{Continuity equation}

$v=$ constant $=-V_{0}$

\section{Momentum equations}

$$
\begin{aligned}
& \frac{\partial u}{\partial t}-V_{0} \frac{\partial u}{\partial y}=v \frac{\partial^{2} u}{\partial y^{2}}+\frac{\pi}{8 \rho} J_{0} M_{0} \exp \left(-\frac{\pi}{a} y\right)+2 \Omega w \\
& \frac{\partial w}{\partial t}-V_{0} \frac{\partial w}{\partial y}=v \frac{\partial^{2} w}{\partial y^{2}}+\frac{\pi}{8 \rho} J_{0} M_{0} \exp \left(-\frac{\pi}{a} y\right)-2 \Omega u
\end{aligned}
$$

Energy equation:

$$
\left\{\begin{array}{l}
\frac{\partial T}{\partial t}-V_{0} \frac{\partial T}{\partial y}=\frac{\kappa}{\rho c_{p}}\left(\frac{\partial^{2} T}{\partial y^{2}}\right)+\frac{\mu}{\rho c_{p}}\left[\left(\frac{\partial u}{\partial y}\right)^{2}+\left(\frac{\partial w}{\partial y}\right)^{2}\right] \\
+\frac{1}{\rho c_{p}} \frac{16 \sigma^{*}}{3 k^{*}} T_{\infty}^{3} \frac{\partial^{2} T}{\partial y^{2}}
\end{array}\right\}
$$

The boundary settings for the prevailing system of equations are:

\section{SN Applied Sciences}

$$
\left\{\begin{aligned}
t>0, u=0, w=0, T & =T_{w} \text { at } y=0 \\
u \rightarrow 0, w \rightarrow 0, T & \rightarrow T_{\infty} \text { at } y \rightarrow \infty
\end{aligned}\right\}
$$

where the density of the fluid is $\rho\left(\mathrm{kg} / \mathrm{m}^{3}\right)$, the thermal conductivity is $\kappa(W / m K)$, the specific heat at the constant pressure is $c_{p}(\mathrm{~J} / \mathrm{Kkg})$, the dynamic viscosity is $\mu(\mathrm{kg} / \mathrm{ms})$, the electrodes current density is $J_{0}\left(A / \mathrm{m}^{2}\right)$, the magnetization of the adjusted magnets is $M_{0}(T)$, and the uniform width of the magnets and electrodes is $a(m)$.

Notably, The radiative heat flux $Q_{r}$ is defined as depicted in Chauhan and Khemchandani [51] by the Rosseland approximation in the form $Q_{r}=-\frac{4 \sigma^{*}}{3 k^{*}}\left(\frac{\partial T^{4}}{\partial y}\right)$, where, mean absorption coefficient $\left(k^{*}\right)$, and Stefan-Boltzmann constant $\left(\sigma^{*}\right)$. The Taylor series expansion with a familiar supposition for $T^{4}$ in terms of $T_{\infty}$ implies $T^{4} \cong 4 T_{\infty}^{3}-3 T_{\infty}^{4}$ as conducted in Hassan et al. [52], which leads, $Q_{r}^{\infty}=-\frac{16 \sigma^{\infty}}{3 k^{*}} T_{\infty}^{3} \frac{\partial T}{\partial y}$.

To get the benefit of explicit FDM in manipulating the Eqs. 1-4 under the boundary conditions 5 , it is essential to ensure a dimensionless conversion of the equations. The following quantities in the dimensionless form are employed for the implementation of the non-dimensionalization process:

$\left\{\begin{array}{l}X=\frac{x}{l}, Y=\frac{y}{L}, U=\frac{u}{U_{0}}, W=\frac{w}{U_{0}}, \tau=\frac{t U_{0}}{I} \\ \theta=\frac{T-T_{\infty}}{T_{w}-T_{\infty}} ; \text { where, } I=\frac{U_{0} L^{2}}{v}, L=\frac{a}{\pi}\end{array}\right\}$

The derived dimensionless system of non-linear PDEs can be expressed as follows: 
$\frac{\partial U}{\partial \tau}-S \frac{\partial U}{\partial Y}=\frac{\partial^{2} U}{\partial Y^{2}}+Z e^{-Y}+2 R W$

$\frac{\partial W}{\partial \tau}-S \frac{\partial W}{\partial Y}=\frac{\partial^{2} W}{\partial Y^{2}}+Z e^{-Y}-2 R U$

$\frac{\partial \theta}{\partial \tau}-S \frac{\partial \theta}{\partial Y}=\frac{1}{P_{r}} \frac{\partial^{2} \theta}{\partial Y^{2}}+E_{c}\left[\left(\frac{\partial U}{\partial Y}\right)^{2}+\left(\frac{\partial W}{\partial Y}\right)^{2}\right]+\frac{4}{3} R_{d} \frac{\partial^{2} \theta}{\partial Y^{2}}$

The dimensionless boundary conditions are noted as:

$\left\{\begin{array}{rc}\tau>0, U=0, W=0, \theta=1 & \text { at } Y=0 \\ U \rightarrow 0, W \rightarrow 0, \theta \rightarrow 0 & \text { at } Y \rightarrow \infty\end{array}\right\}$

The dimensionless equations disclose several dimensionless parameters with their respective physical meaning. The dimensionless parameters have alluded to below: $R=\frac{\Omega L^{2}}{v}$ (rotational parameter), $P_{r}=\frac{v \rho c_{p}}{\kappa}$ (Prandtl number), $E_{c} \stackrel{v}{=} \frac{\mu l U_{0}}{\rho c_{p} L^{2}\left(T_{w}-T_{\infty}\right)}$ (Eckert number), $R_{d} \stackrel{\kappa}{=} \frac{4 \sigma^{*} T_{\infty}^{3}}{k^{*} \rho c_{p}}$ (radiation parameter), $S=\frac{V_{0}^{\infty} L}{v}$ (suction parameter), and $Z=\frac{J_{0} M_{0} a^{2}}{8 \pi \rho U_{0} v}$ (modified Hartmann number); see Refs. [1-3].

\section{Quantities of engineering curiosity}

The entities which have effective importance in miscellaneous Engineering purposes are stated here. The shear stress phenomena feature the landmarks of the fluid layer vicinity to the plate. The Nusselt number stands for the counting of heat transfer by the convection process. The primary velocity $(X$-direction), secondary velocity ( $Z$-direction), and temperature profile respectively yield the primary shear stress ( $X$-direction) as $\tau_{L X}=\mu\left(\frac{\partial U}{\partial Y}\right)_{Y=0}$, secondary shear stress (Z-direction) as $\tau_{L Z}=\mu\left(\frac{\partial W}{\partial Y}\right)_{Y=0^{\prime}}$, and Nusselt number as $N u_{L}=-\mu\left(\frac{\partial \theta}{\partial Y}\right)_{Y=0}$.

\section{Numerical computation technique}

The discretization of the system of coupled non-dimensional PDEs (Eqs. 7-9) has been accomplished in both time and space by the explicit FDM $[7,48]$. Time-dependent iterative computations are reckoned to find the values of the set of finite difference equations that are gained by the use of MATLAB simulations. In that context, the furcation of the $B L$ region is implemented to construct the grid of lines perpendicular to $Y$-axis, as shown in Fig. 2 .

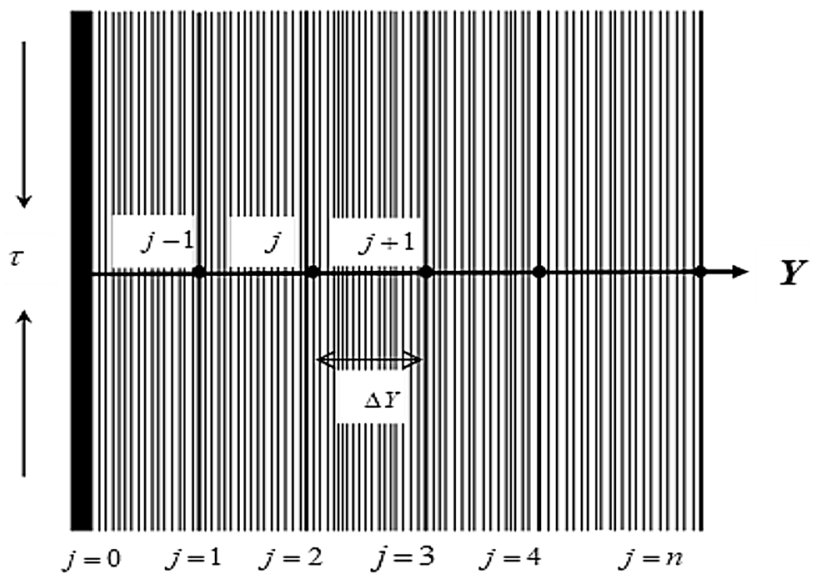

Fig. 2 FDM grids

Here the maximum width of the $B L$ is arbitrarily deliberated as $Y_{\max }(=2)$ i.e. $Y$ ranges from 0 to 2. Numerical iterations for the discretized equations are conducted with a grid number $n=60$. The choice of taking $n=60$ is based on the mesh sensitivity experiment (Sect. 6.1). Based on the grid number, the mesh size in $Y$-direction is taken as $\Delta Y=0.033(0 \leq x \leq 60)$ (constant); regarding the infinitesimal time-step, $\Delta \tau=0.0001$.

The territory within the $\mathrm{BL}$ has been placed with a finite number of a set of points. The FDM schemes are constructed by using backward difference style for single-order derivatives and central difference style for higher-order derivatives. Time-domain effects on flow equations are reckoned such that the former time values are imported to calculate the subsequent time values.

\section{Analysis of stability and convergence criteria}

Without addressing the criteria for stability and convergence on the constructed finite difference schemes, the study will become imperfect. For the constant grid space and time difference, the stability analysis (RezaE-Rabbi et al. [11]) has been conducted, and the final consequence is given below:

$\frac{2 \Delta \tau}{P_{r}(\Delta Y)^{2}}+\frac{4}{3} R_{d} \frac{2 \Delta \tau}{(\Delta Y)^{2}}-S \frac{\Delta \tau}{\Delta Y} \leq 1$

Applying $\Delta Y=0.033, \Delta \tau=0.0001$, and the initial conditions, the inequality 15 produces the converging restrictions on pertinent quantities as $P_{r} \geq 0.19$, $R_{d} \geq 0.1, S \geq 1, E_{c}=0.01$ and $0<R \leq 0.1$. These converging ranges are used to obtain the parameters effect with 
the steady-state value of time as well as with suitable mesh size on the flow model equations.

\section{Results and discussions}

Exploration of $\mathrm{BL}$ incompressible and electrically conducting flow wielding through an infinite Riga plate in a rotating system under the action of MHD phenomena with suction and thermal radiation have been instituted numerically. This study has been constructed to deal with some Newtonian fluid, for which the BL flow nature reflects the flow criteria through the vertical flow monitoring device (Riga plate). Normalization of the governing equations has been accomplished under the suitable boundary layer approximations. For the purpose of investigating the mechanical characteristics of the constructed mathematical structure, the steady-state behavior of pertinent physical parameters on dimensionless primary velocity $(U)$, secondary velocity $(W)$, and the temperature $(\theta)$ is analyzed. At first, the sensitivity test on meshes has been demonstrated to attain the perfect grid number for the execution of numerical performance. Then, to acquire the sloution in steady-state, the sensitivity test on time has been performed. Thereafter, the effects of some pertinent parameters like as, modified Hartmann number $(Z)$, suction parameter $(S)$, and rotational parameter $(R)$ on both the velocities and energy field, simultaneously on both the shear stresses and Nusselt number are graphically demonstrated with descriptions. To make this study concise, the impacts of the rest of the parameters like radiation parameter $\left(R_{d}\right)$, Eckert number $\left(E_{c}\right)$, and Prandtl number $\left(P_{r}\right)$ have not been included. At last, the present results have been compared in tabular form with published results.

\subsection{Mesh sensitivity}

To justify the compatible number of grid lines i.e. the value of $n$, the computational procedure is continued for triplicate individual values of grids and the values are $n=60$, $n=70$ and $n=80$ which are sketched in Figs. 3, 4, and 5 for primary velocity, secondary velocity, and temperature field. The calculation is performed with the assumption of $Z=3.00, R=0.01, R_{d}=2.00, E_{c}=0.01, P_{r}=7.00$ and $S=1.00$. A situation of mesh independence is observed among these curves. According to this situation, $n=60$ is chosen as the perfect grid space line. In further numerical computations, the results of both the velocities and temperature field along with both the shear stresses and Nusselt number have been carried out for $n=60$.

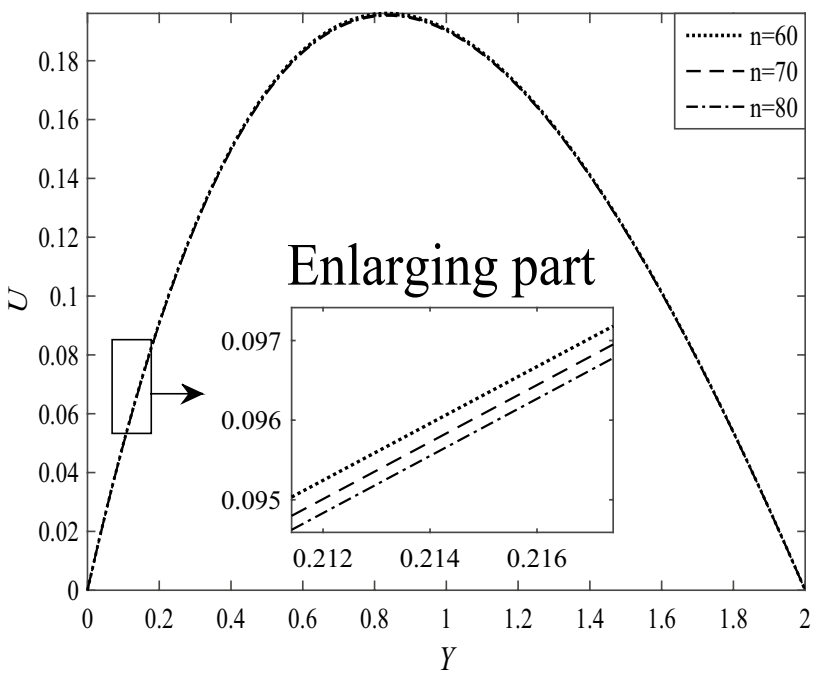

Fig. 3 Sensitivity test for mesh on primary velocity

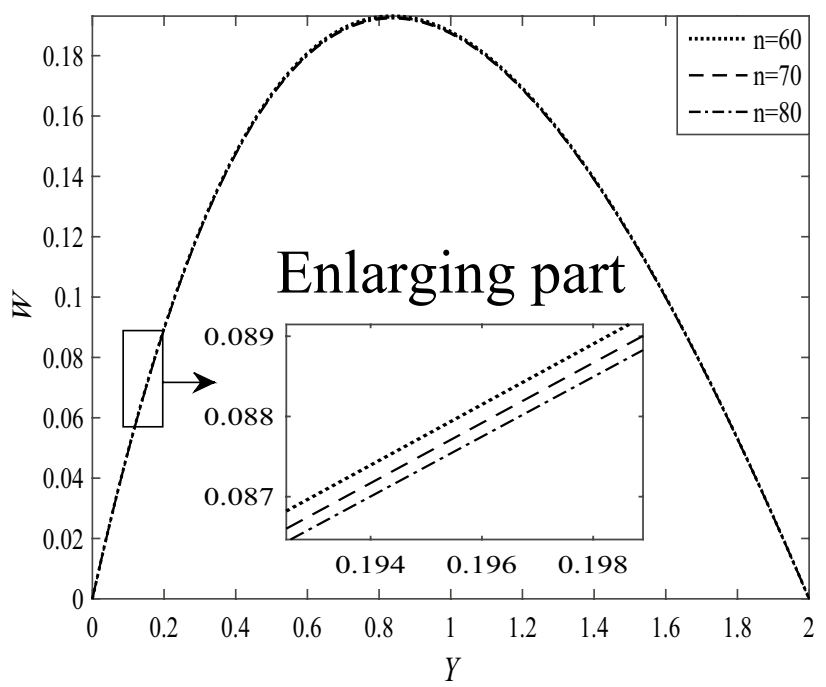

Fig. 4 Sensitivity test for mesh on secondary velocity

\subsection{Time sensitivity}

In order to acquire the steady-state solutions, the computational procedure is conducted for six individual non-dimensional time step such as $\tau=0.50,1.00,1.50$, 2.00, 2.50, and 3.00, where $Z=3.00, R=0.01, R_{d}=2.00$, $E_{c}=0.01, P_{r}=7.00$, and $S=1.00$. It is noticed from Figs. 6,7 , and 8 that the resulting computations for $U, W$ and $\theta$ show a tiny change after $\tau=1.50$ also show an ineffective change after $\tau=2.00$. Upon observing the situation, the time value $\tau=2.00$ is taken as the steadystate time value for all the profiles. Moreover, the temperature field is found to gain steady-state prior to the primary and secondary velocity profiles. 


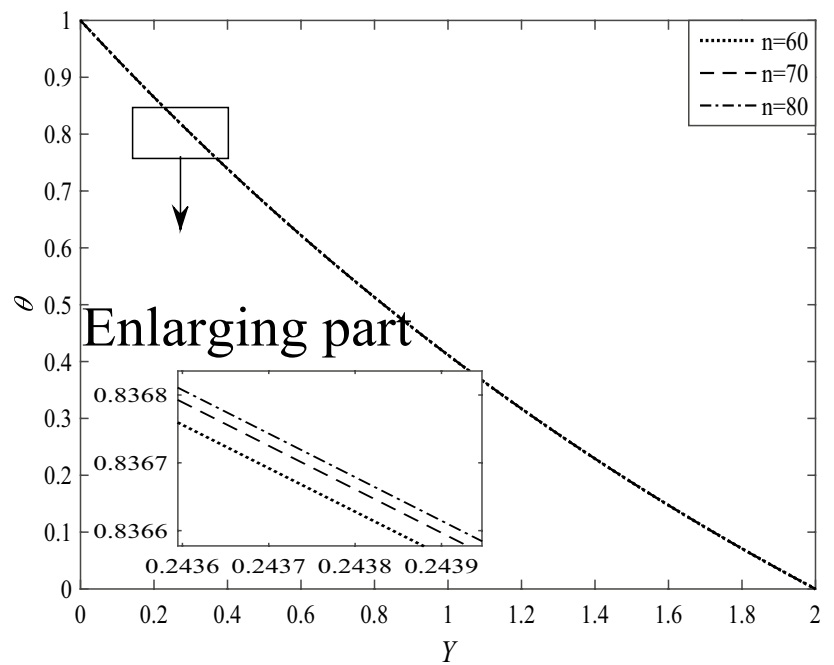

Fig. 5 Sensitivity test for mesh on temperature profile

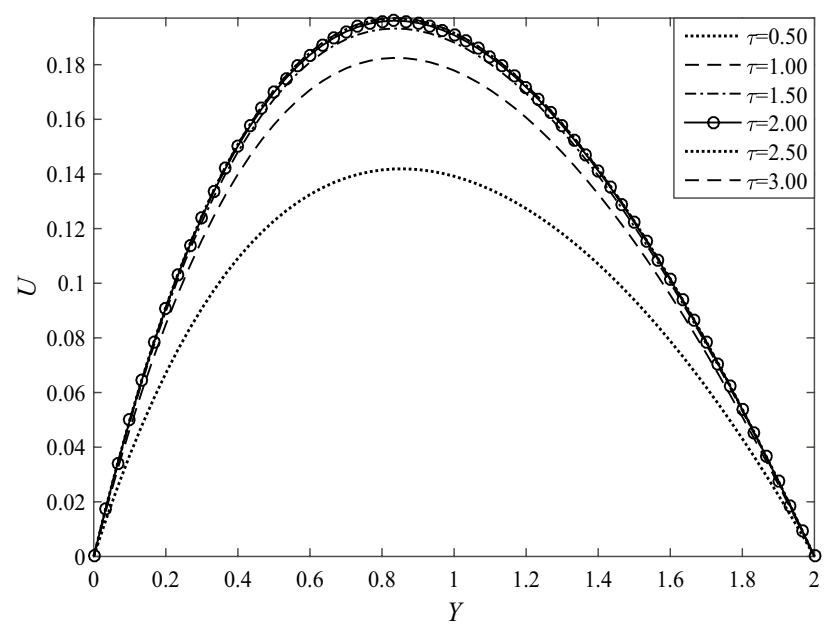

Fig. 6 Sensitivity test for time on primary velocity

\subsection{Validation test (comparison)}

The current section is discussed to analyze the prescribed results of the present study with the numerical results of Islam et al. [12]. The qualitative and quantitative similarity, as well as dissimilarity, is portrayed in Fig. $9(a, b)$. The prescription of both the results show an excellent appearance in the qualitative sense. In a quantitative sense the results are not identical, since the present study concerns with the action of suction velocity while the study of Islam et al. [12] doesn't. Furthermore, all the possible sensitivity analyses have been tested and reported rigorously, which emphasize the exactness of the presented numerical performance.

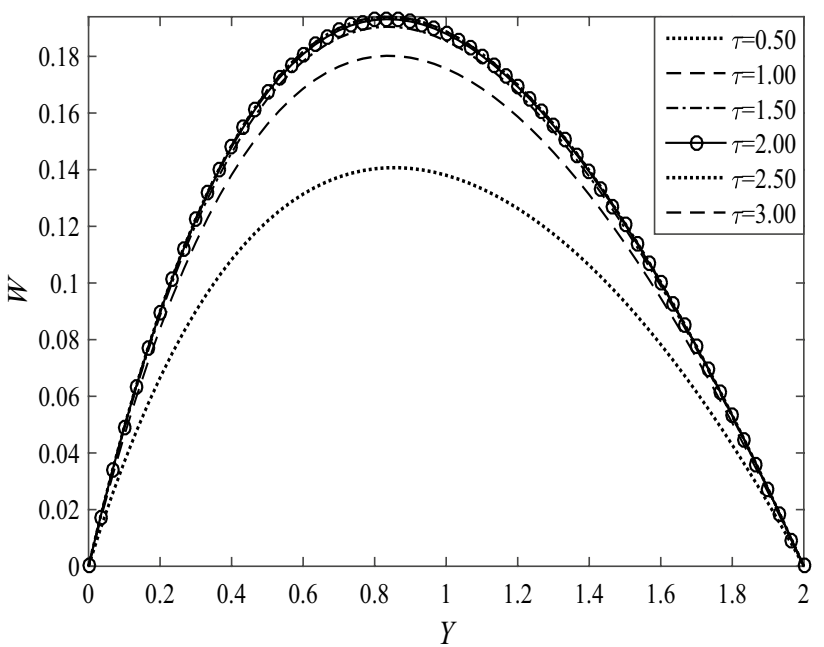

Fig. 7 Sensitivity test for time on secondary velocity

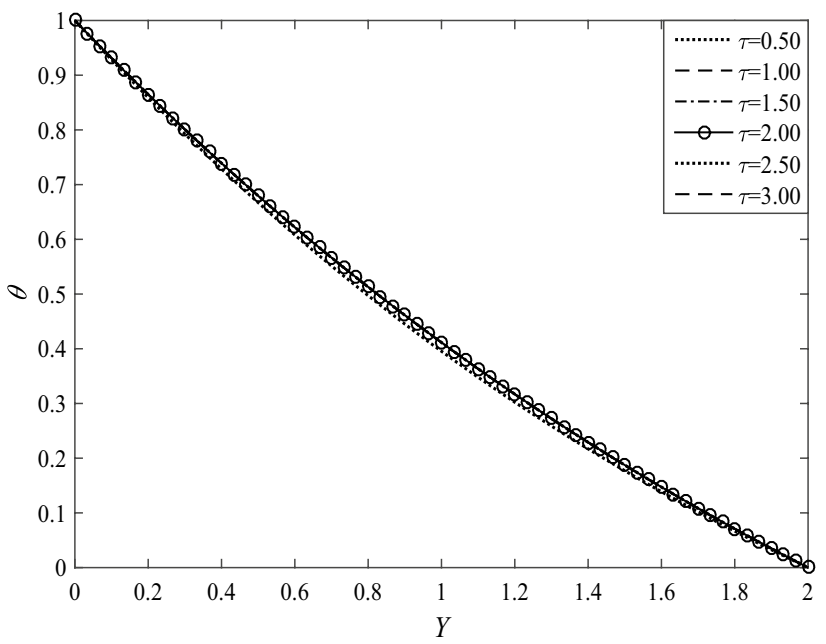

Fig. 8 Sensitivity test for time on temperature profile

\subsection{Effects of affined parameters}

To clarify the physical outlines of this paper, the impacts of three parameters namely modified Hartmann number $(Z)$, rotational parameter $(R)$, and suction parameter $(S)$ on both the velocity profiles $(U, W)$ (primary and secondary), and temperature field $(\theta)$ along with both the local shear stresses $\left(\tau_{L X}, \tau_{L Z}\right)$ (primary and secondary), and local Nusselt number $\left(N u_{L}\right)$ are demonstrated and described in words by adopting the Prandtl number $\left(P_{r}=7.00\right)$, radiation parameter $\left(R_{d}=2.00\right)$ and Eckert number $\left(E_{c}=0.01\right)$ (see Figs. 10(a-f)-12(a-f)).

The impacts of Modified Hartmann number on primary velocity profile, local primary shear stress, secondary velocity profile, local secondary shear stress, temperature, and 


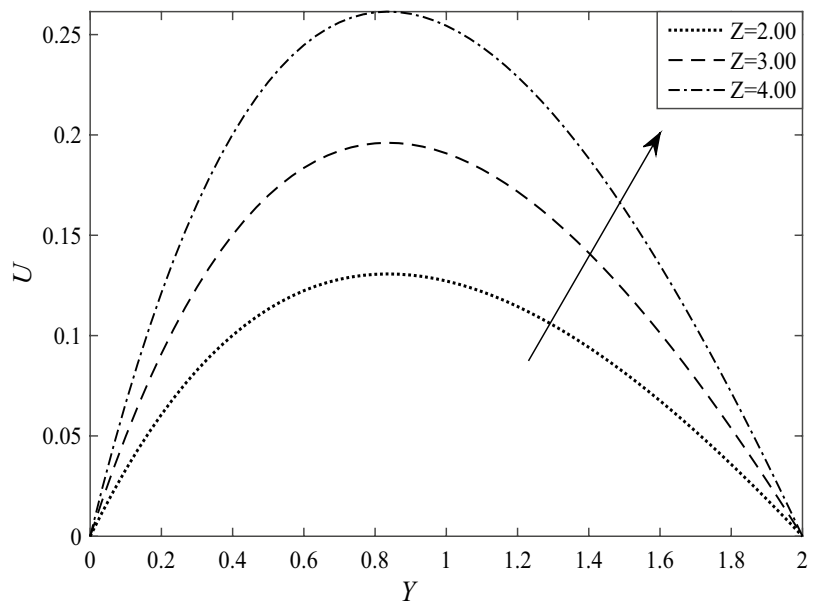

(a)

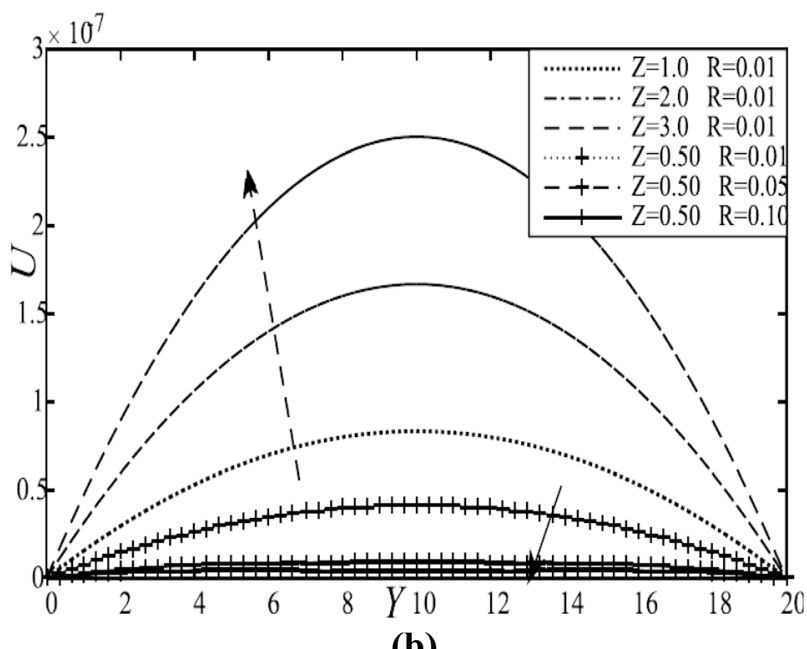

(b)

Fig. 9 Comparison of the effect of ( $Z$ ) on primary velocity between a (present study) and b (reprinted from Islam et al. [12], with the permission of AIP Publishing)

local Nusselt number are sketched in Fig. 10(a-f), where, $R_{d}=2.00, R=0.01, E_{c}=0.01, P_{r}=7.00$, and $S=1.00$ at time $\tau=2.00$. Taking aim on Fig. 10(a,b,c,d), it is reckoned that the primary velocity, primary shear stress, secondary velocity, and secondary shear stress substantially rise while the increasing estimations of the modified Hartmann number $(Z)$ are adopted. The inner physics supports this acceleration of velocities with the uprising of modified Hartmann number $(Z)$ because positive assumptions of $(Z)$ notifies favoring flow criteria. The physical understanding behind this fact is that comparatively stronger estimations of $(Z)$ causes strengthen in the electric field which results in the acceleration of velocities. With the uplift of the magnetic field, a simultaneous uplifting happens in the electromagnetic field and consequently, the generation of Lorentz force produces extra surface tension that later specifies the flow acceleration. Temperature distribution critically rises by the increment of the modified Hartmann number $(Z)$ while the local Nusselt number reduces slowly (see Fig. 10(e,f)).

Again, the influences of the rotational parameter on primary velocity profile, local primary shear stress, secondary velocity profile, local secondary shear stress, temperature, and local Nusselt number are demonstrated in Fig. 11(a-f), where $Z=2.00, R_{d}=2.00, E_{c}=0.01, P_{r}=7.00$ and $S=1.00$ at time $\tau=2.00$. Figure $11(\mathrm{a}, \mathrm{b})$, pointing out the enhancing phenomena of the primary velocity and the local primary shear stress while the rising values of the rotational parameter $(R)$ take place. Opposite occurrence is marked on the secondary velocity and the local secondary shear stress for the rotational parameter $(R)$ in Fig. 11-c and d. These facts imply that the causation of heighten in primary velocity occurs due to the motility of rotation while secondary velocity obstructs this happening. Actually, in primary velocity, enhancement in the rotational parameter $(R)$ indicates enhancing Coriolis force that results in the development of rotational velocity. Due to this boosting in rotational velocity, the kinetic energy of the fluid rises that outcomes in the expected elevation in primary velocity. Furthermore, the temperature field reduces slowly with the enhancement of the rotational parameter $(R)$ while the local Nusselt number rises a bit by the enhancement of the rotational parameter $(R)$ (see Fig. 11-e and f).

Furthermore, the impacts of the suction parameter on primary velocity profile, local primary shear stress, secondary velocity profile, local secondary shear stress, temperature, and local Nusselt number are presented in Fig. 12(a-f), where $Z=2.00, R_{d}=2.00, E_{c}=0.01, P_{r}=7.00$ and $R=0.01$ at time $\tau=2.00$. From Fig. $12(\mathrm{a}, \mathrm{c}, \mathrm{e})$, it is noticed that the primary velocity, secondary velocity, and temperature field reduce with the enhancement of the suction parameter $(S)$. While wall suction increases, the velocity of the flow experiences retardation on it that comes to an outcome of narrowing the momentum boundary layer. Suction specifies fluid transportation to a higher pressure regime from a lower pressure regime. The hike in the suction parameter ensures the increasing transportation of fluid to the regime of higher pressure. The fluid movement in the direction of the permeable wall (Riga plate) cuts down its volume and later diminishes the flow velocity. The decrement in velocity affects the fluid temperature and pulls it down. On contrary, From Fig. 12(b,d,f), it is perceived interestingly that, the local primary shear stress, local secondary shear stress, and local Nusselt number rise with the increment of the suction parameter (S). 


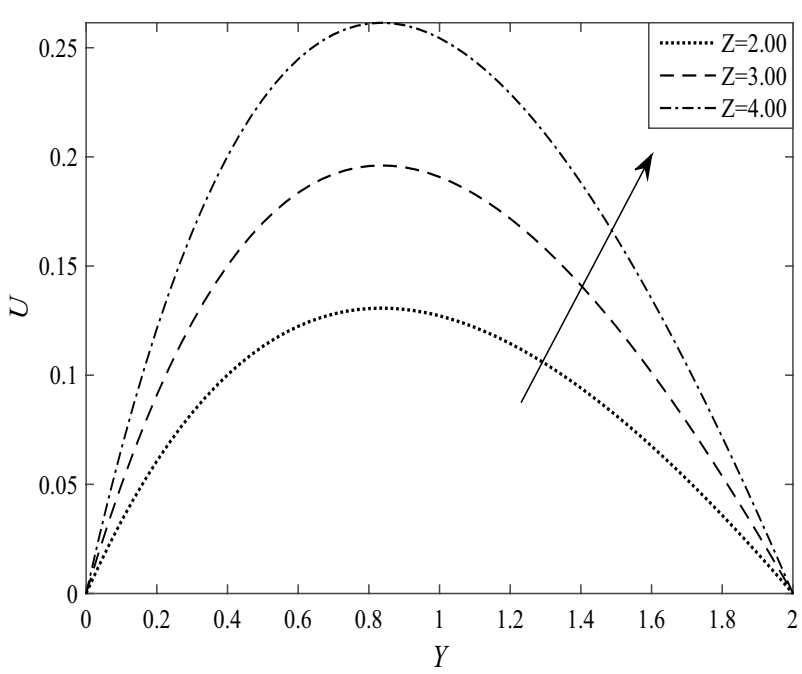

(a)

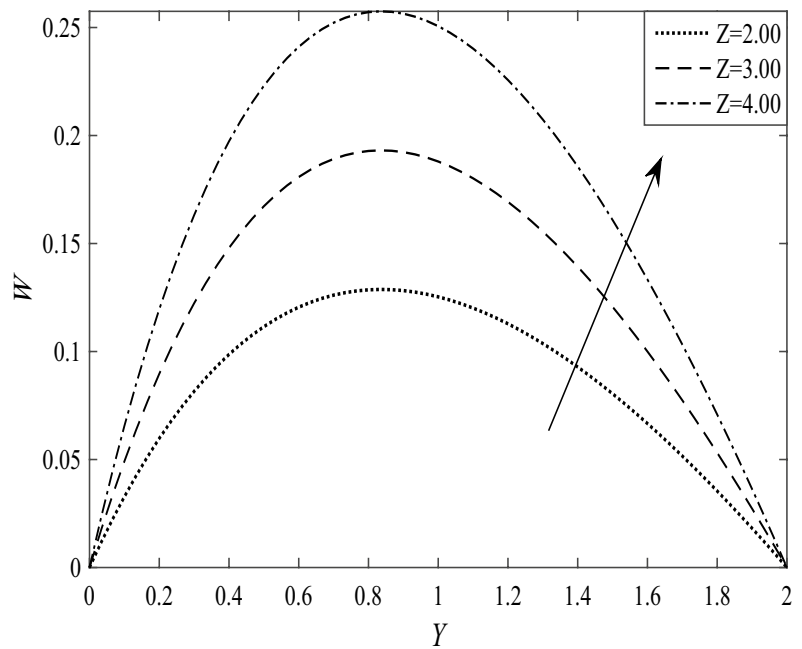

(c)

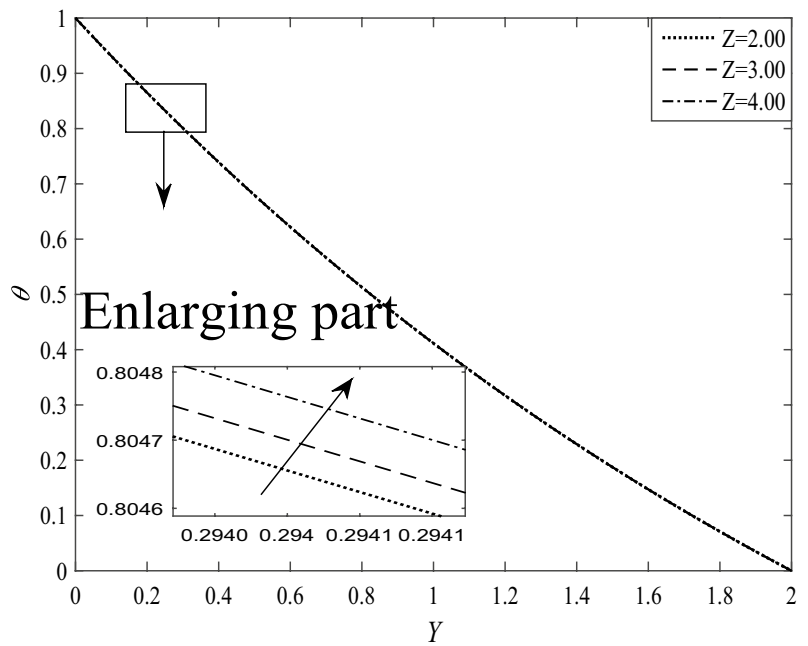

(e)

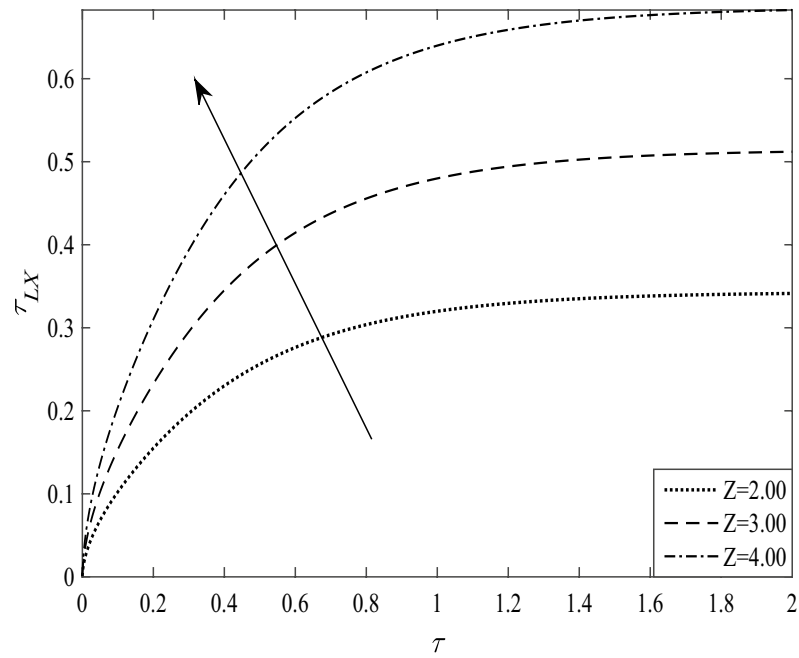

(b)

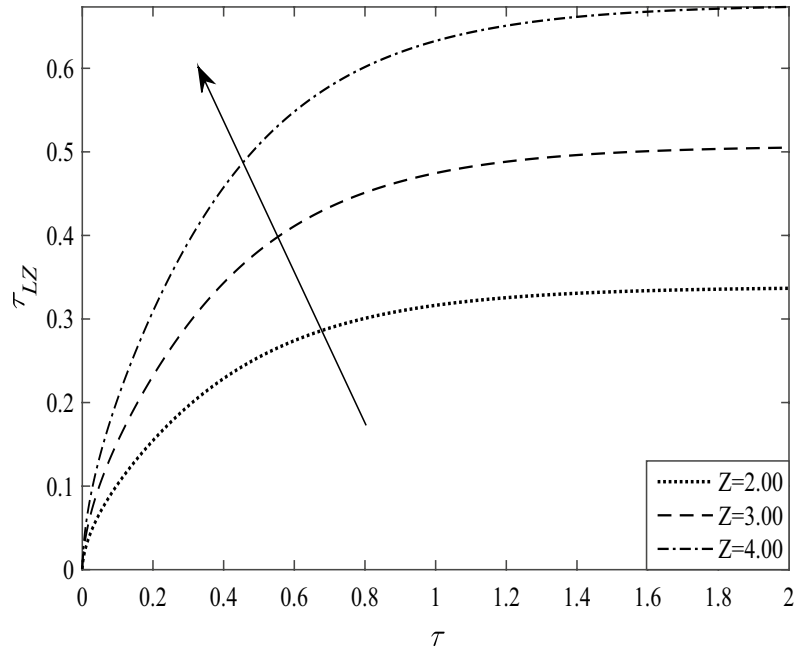

(d)

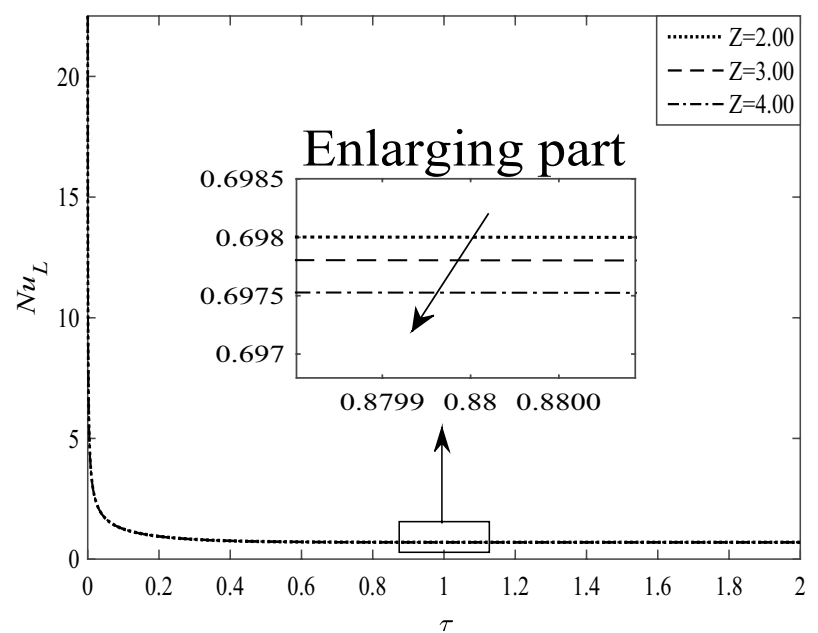

(f)

Fig. 10 Effect of $(Z)$ on a $U ;$ b $\tau_{L X} ; \mathbf{c} W ; \mathbf{d} \tau_{L Z} ;$ e $\theta$; and $\mathbf{f} N u_{L} ;$ where $R_{d}=2.00, E_{C}=0.01, P_{r}=7.00, S=1.00$, and $R=0.01$ at time $\tau=2.00$ (steady-state) 


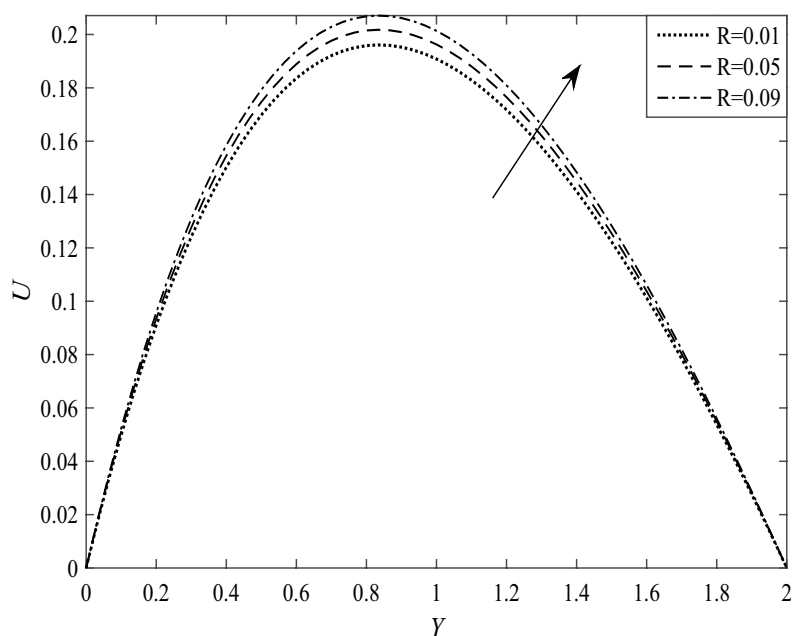

(a)

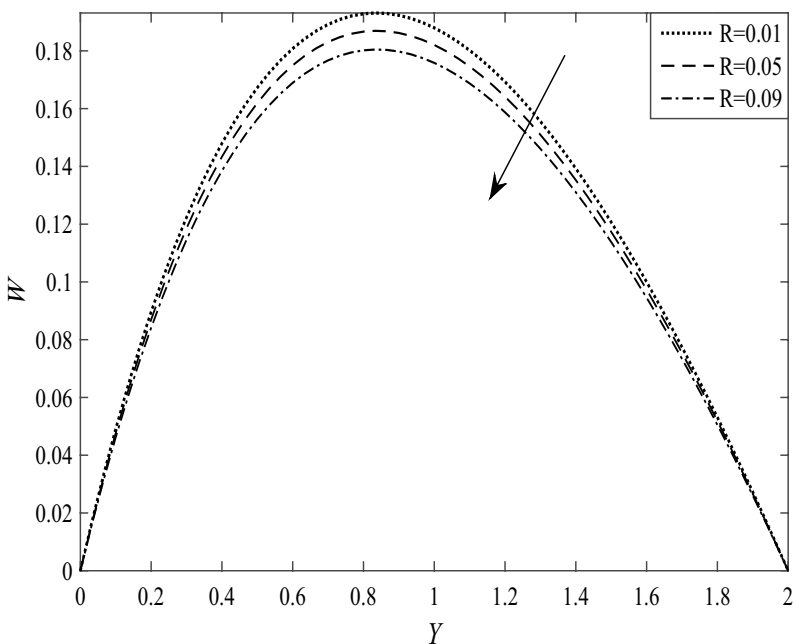

(c)

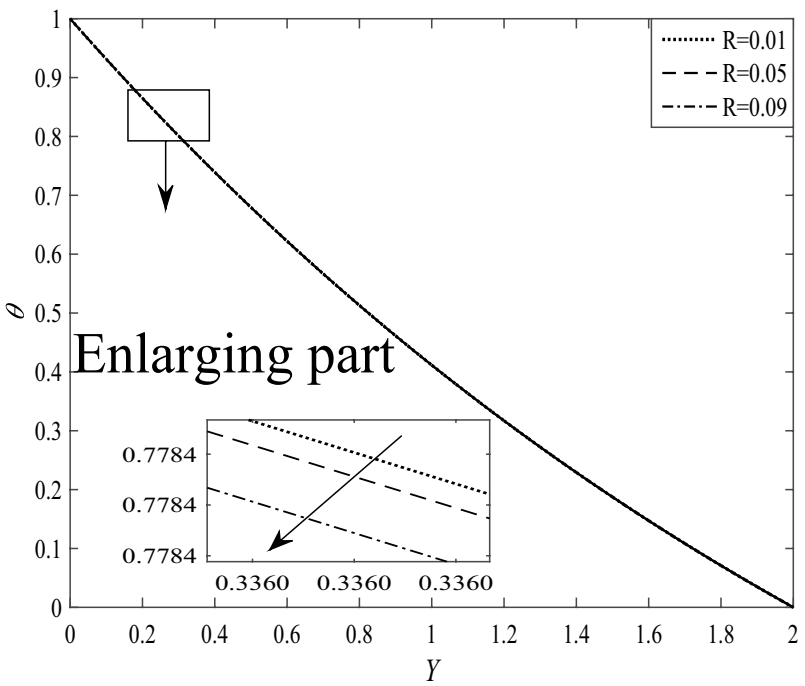

(e)

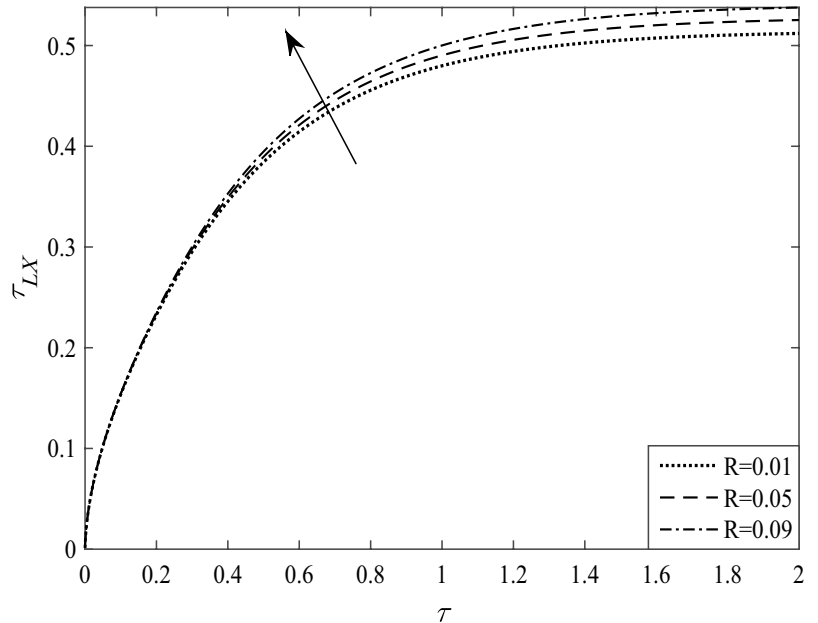

(b)

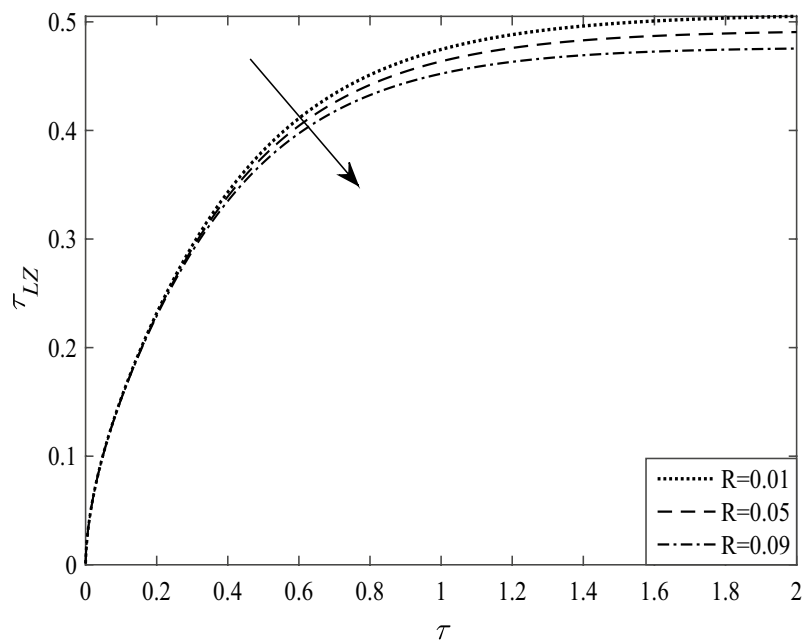

(d)

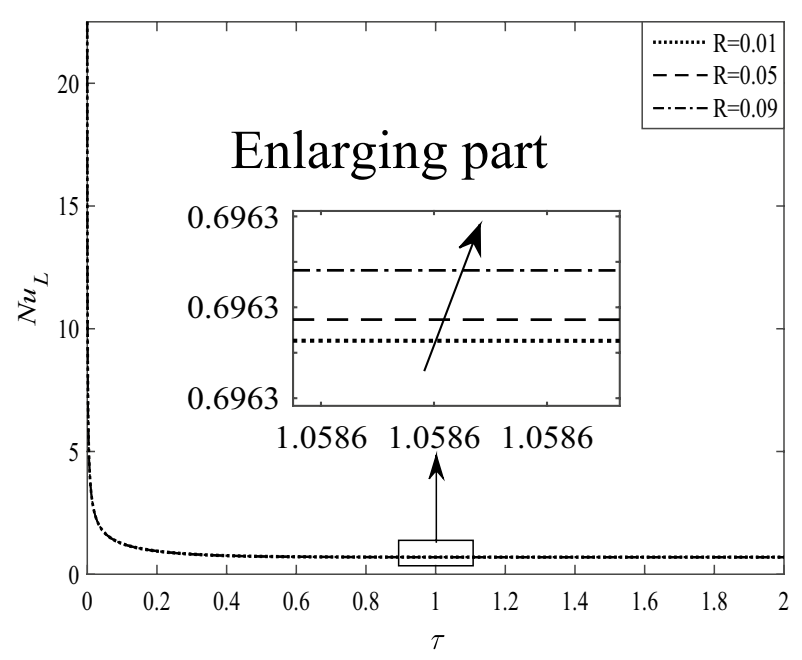

(f)

Fig. 11 Effect of $(R)$ on a $U ; \mathbf{b} \tau_{L X} ; \mathbf{c} W ; \mathbf{d} \tau_{L Z} ;$ e $\theta$; and $\mathbf{f} N u_{L} ;$ where $Z=2.00, R_{d}=2.00, E_{c}=0.01, P_{r}=7.00$, and $S=1.00$ at time $\tau=2.00$ ( steady-state) 


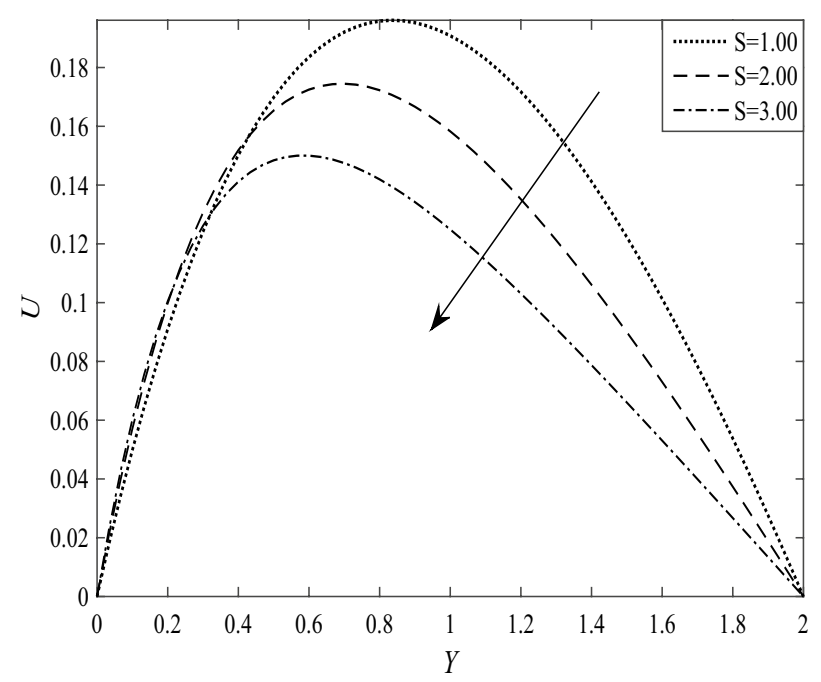

(a)

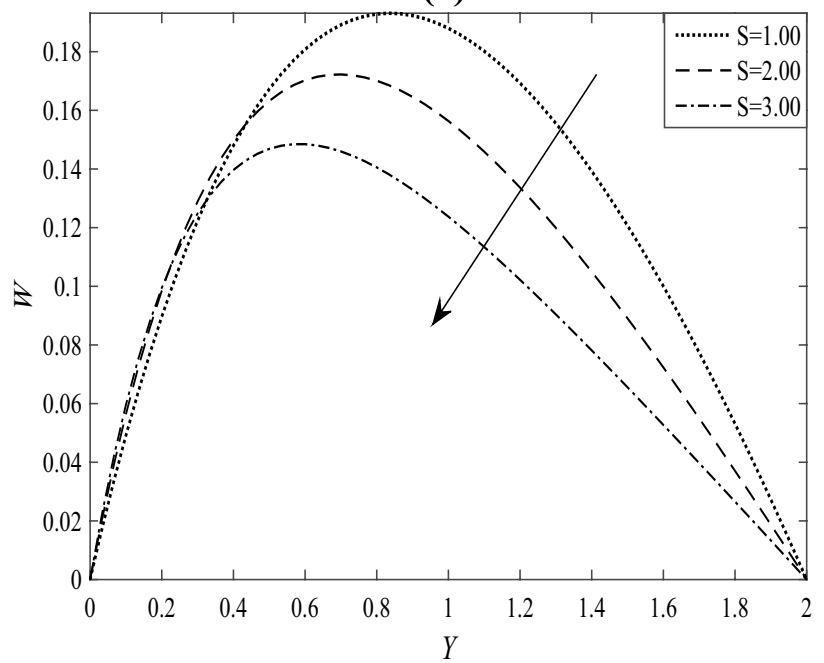

(c)

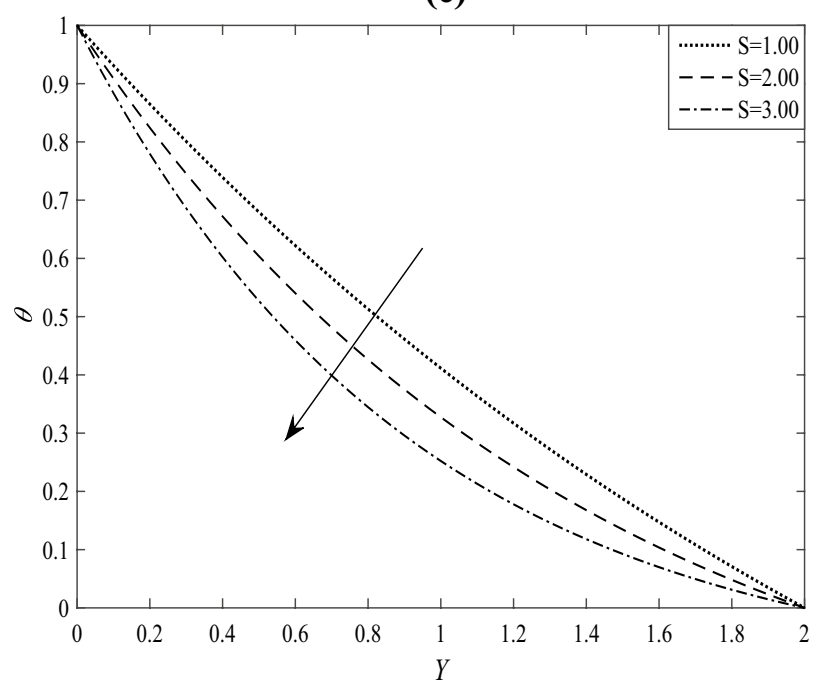

(e)

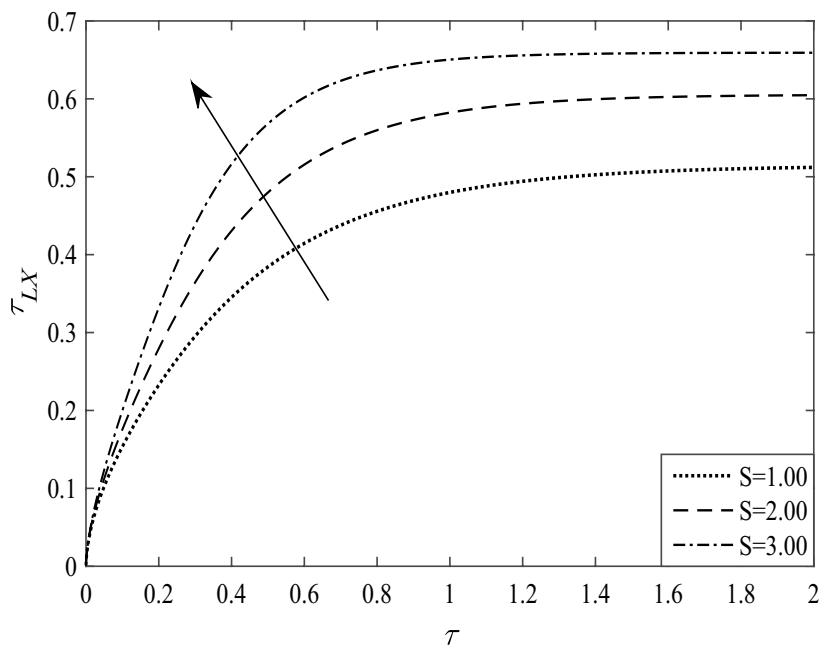

(b)

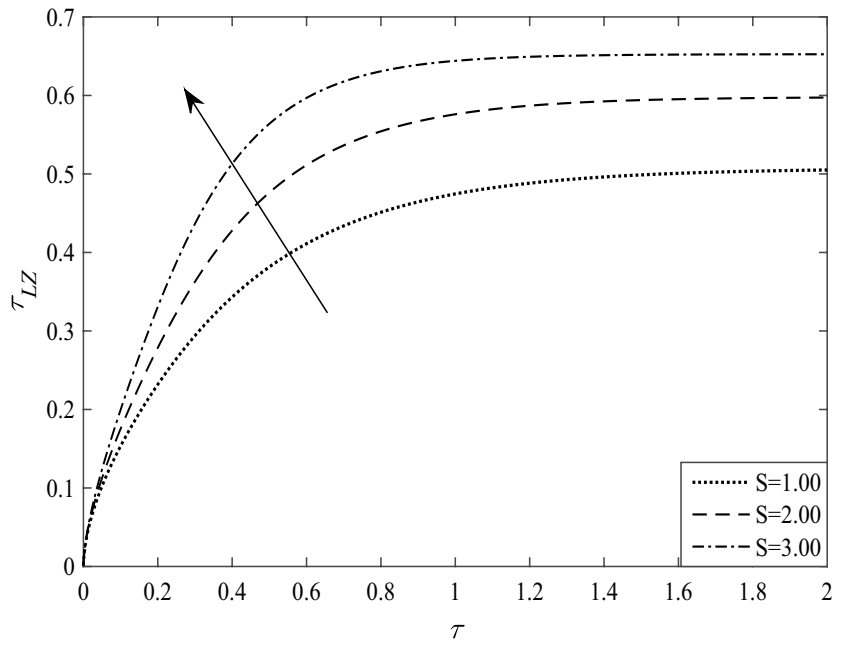

(d)

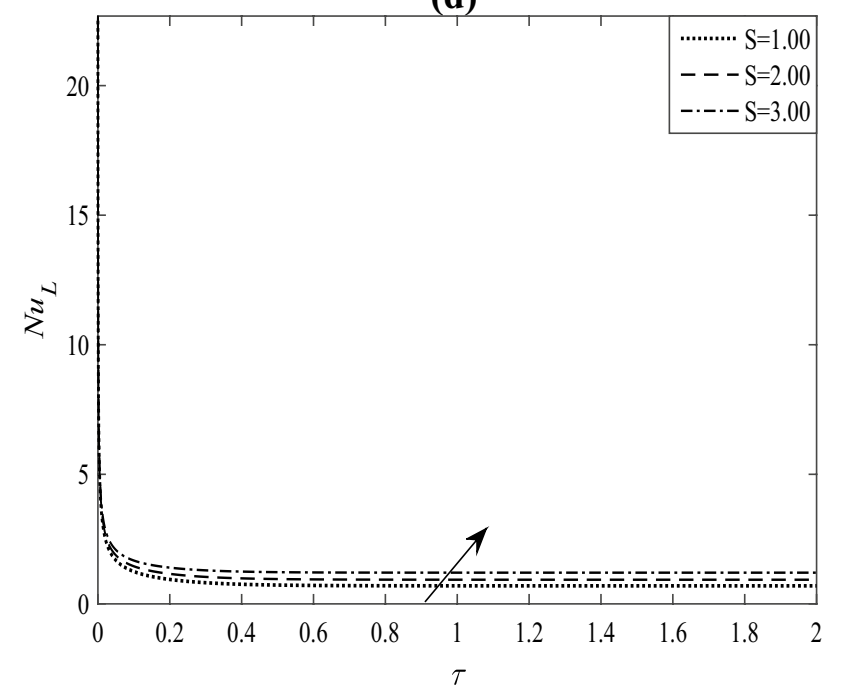

(f)

Fig. 12 Effect of (S) on (a) $U$; (b) $\tau_{L X}$; (c) $W$; (d) $\tau_{L Z}$; (e) $\theta$; and (f) $N u_{L}$; where $Z=2.00, R_{d}=2.00, E_{c}=0.01, P_{r}=7.00$, and $R=0.01$ at time $\tau=2.00$ (steady-state) 
Table 1 Comparison

\begin{tabular}{lllll}
\hline $\begin{array}{l}\text { Output } \\
\text { Effect on }\end{array}$ & $\begin{array}{l}\text { Present } \\
\text { Results }\end{array}$ & $\begin{array}{l}\text { Bhatti et al. } \\
{[21]}\end{array}$ & $\begin{array}{l}\text { Abbas } \\
\text { et al. } \\
{[19]}\end{array}$ & Wakif et al. [42] \\
\hline \multicolumn{2}{l}{ Suction Parameter(S) } & & & \\
$U$ & Dec. & Dec. & Dec. & Dec. \\
$\theta$ & Dec. & & Dec. & Dec. \\
$\tau_{L X}$ & Inc. & & Inc. \\
$N u_{L}$ & Inc. & & Inc. \\
\hline
\end{tabular}

(Inc. means Increasing and Dec. means Decreasing)

\subsection{Overall qualitative comparison}

To claim the validity of the present findings, a qualitative comparison with published studies have been presented in Table 1. This study involves a new investigation on MHD fluid flow towards a radiating Riga plate with rotational impact while Bhatti et al. [21] investigated the irrotational EMHD nanofluid flow by considering the thermal radiation impacts on a Riga plate; Abbas et al. [19] reckoned the generation of entropy due to the nanofluidic flow through a Riga plate of horizontal orientation, and Wakif et al. [42] examined EMHD flow that subjected to suction for permeable and moving Riga plate. To make this comparison section as brief as possible, the effect of the suction parameter $(S)$ is analyzed only.

\section{Conclusions}

In this study, the EMHD rotational and unsteady fluid flow through an infinitely long permeable Riga plate with thermal radiation has been investigated by employing explicit FDM. The only responsible wiellding force for the flow is the body force that is generated by the electromagnetic actuator. The presented flow model is being subjugated by uniform suction, thermal radiation with the system rotation. The transition of the nature of the flow from the state of unsteadiness to the state of the complete steady-state has been gained for the velocities (primary and secondary) in a smooth swift-moving way (see Figs. 6 and 7) while for the temperature it is as fast as instant (see Fig. 8). The converging ranges for the numerical solutions are $P_{r} \geq 0.19$, $R_{d} \geq 0.1, S \geq 1, E_{c}=0.01$ and $0<R \leq 0.1$. On the basis of the results and discussions, some salient observations are stated below:

1. The fastest steady-state is gained by the temperature distribution among all the profiles. All the profiles have reached steady-state within $\tau=2.00$.
2. Converging solutions occur for the relevant restrictions as, $P_{r} \geq 0.19, R_{d} \geq 0.1, S \geq 1, E_{c}=0.01$ and $0<R \leq 0.1$.

3. The increasing value of $(Z)$ and $(R)$ both cause an increment in primary velocity while local primary shear stress slowly increases. Also, the reason for the reduction of the primary velocity is $(S)$ but local primary shear stress shows uplifting nature.

4. Enhancement in the secondary velocity and a slow rise in the local secondary shear stress have been marked whilst the estimations of $(Z)$ rises there out both of them show a decreasing effect for the enhancement of $(R)$. Moreover, the secondary velocity falls for the enhancement of $(S)$ while the local secondary shear stress rises.

5. The temperature profile boosts up with the increment of $(Z)$ whilst reduces with the enhancement of both the $(R)$ and $(S)$.

6. The local Nusselt number reduces for the rise of $(Z)$ while rises with the increment of $(R)$ and $(S)$ both.

The future direction of this research is to the possible analysis of the EMHD flow of rotating fluid through the inclined Riga plate with the incorporation of a non-uniform heat source.

\section{Declaration}

Conflict of interest The authors declare that they have no conflict of interest.

Open Access This article is licensed under a Creative Commons Attribution 4.0 International License, which permits use, sharing, adaptation, distribution and reproduction in any medium or format, as long as you give appropriate credit to the original author(s) and the source, provide a link to the Creative Commons licence, and indicate if changes were made. The images or other third party material in this article are included in the article's Creative Commons licence, unless indicated otherwise in a credit line to the material. If material is not included in the article's Creative Commons licence and your intended use is not permitted by statutory regulation or exceeds the permitted use, you will need to obtain permission directly from the copyright holder. To view a copy of this licence, visit http://creativecommons .org/licenses/by/4.0/.

\section{References}

1. Mollah MT (2019) EMHD laminar flow of Bingham fluid between two parallel Riga plates. Int J Heat Technol. 37(2):641-648

2. Afridi M, Qasim M, Hussanan A (2018) Second law analysis of dissipative flow over a riga plate with non-linear rosseland thermal radiation and variable transport properties. Entropy 20(8):615. https://doi.org/10.3390/e20080615

3. Abbas T, Bhatti MM, Ayub M (2017) Aiding and opposing of mixed convection Casson nanofluid flow with chemical reactions through a porous Riga plate. Proc Inst Mech 
Engineers, Part E: J Process Mech Eng 232(5):519-527. https:// doi.org/10.1177/0954408917719791

4. Gayatri M, Reddy KJ, Babu MJ (2020) EMHD flow of Carreau fluid over a stretching sheet in the presence of thermal radiation. International conference on mathematical sciences and applications (ICMSA-2019). https://doi.org/10.1063/5.0014705

5. Turkyilmazoglu M (2011) Thermal radiation effects on the timedependent MHD permeable flow having variable viscosity. Int J Therm Sci 50(1):88-96. https://doi.org/10.1016/j.ijthermals ci.2010.08.016

6. Seth GS, Kumbhakar B, Sarkar S (2014) Unsteady hydromagnetic natural convection flow with heat and mass transfer of a thermally radiating and chemically reactive fluid past a vertical plate with newtonian heating and time dependent free-stream. Int J Heat Technol. 32(12):87-94

7. Mollah MT, Poddar S, Alam IMM, MM, (2021) Non-isothermal Bingham fluid flow between two horizontal parallel plates with Ion-slip and Hall currents. SN Appl Sci. https://doi.org/10.1007/ s42452-020-04012-2

8. Turkyilmazoglu M (2016) Natural convective flow of nanofluids past a radiative and impulsive vertical plate. J Aerosp Eng 29(6):04016049. https://doi.org/10.1061/(asce)as.19435525.0000643

9. Izadi M, Shahivand I, Mehryan SA, Hasan MS, Lorenzini G (2020) Magneto-hydrodynamic flow of micropolar nanofluid containing motile microorganisms passing over a vertical stretching sheet with magnetic field dependent viscosity. J Eng Thermophys 29(4):632-656. https://doi.org/10.1134/ S1810232820040116

10. Ali A, Jana RN, Das S (2020) Hall effects on radiated magnetopower-law fluid flow over a stretching surface with power-law velocity slip effect. Multidiscip Model Mater Struct 17(1):103125. https://doi.org/10.1108/MMMS-01-2020-0005

11. Reza-E-Rabbi S, Ahmmed SF, Arifuzzaman SM, Sarkar T, Khan MS (2019) Computational modelling of multiphase fluid flow behaviour over a stretching sheet in the presence of nanoparticles. Eng Sci Technol Int J. https://doi.org/10.1016/j.jestc h.2019.07.006

12. Islam MM, Khatun S, Mollah MT, Alam MM (2019) Fluid flow along the Riga plate with the influence of magnetic force in a rotating system. AIP Conf Proc 2121(1):050002. https://doi. org/10.1063/1.5115889

13. Gailitis A, Lielausic O (1961) On a possibility to reduce the hydrodynamical resistance of a plate in an electrolyte. Appl Magnetohydrodyn Rep Phys Inst Riga 12:143-146

14. Wang Y, Hayat T (2008) Fluctuating flow of a Maxwell fluid past a porous plate with variable suction. Nonlinear Anal Real World Appl 9(4):1269-1282. https://doi.org/10.1016/j.nonrw a.2007.02.016

15. Deswita L, Nazar R, Ishak A, Ahmad RR (2010) Similarity solutions for mixed convection boundary layer flow over a permeable horizontal flat plate. Appl Math Comput 217(6):26192630. https://doi.org/10.1016/j.amc.2010.07.076

16. Pantokratoras $A$ (2011) The blasius and sakiadis flow along a riga-plate. Prog Comput Fluid Dyn 11(5):329-333. https://doi. org/10.1504/PCFD.2011.042184

17. Magyari E, Pantokratoras A (2011) Aiding and opposing mixed convection flows over the Riga-plate. Commun Nonlinear Sci Numer Simul 16(8):3158-3167. https://doi.org/10.1016/j.cnsns .2010 .12 .003

18. Vadher PA, Deheri GM, Patel RM (2010) Performance of hydromagnetic squeeze films between conducting porous rough conical plates. Mechanica 45:767-783. https://doi. org/10.1007/s11012-010-9279-y

19. Abbas T, Ayub M, Bhatti MM, Rashidi MM, Ali MES (2016) Entropy generation on nanofluid flow through a horizontal
Riga plate. Entropy 18(6):1-11. https://doi.org/10.3390/e1806 0223

20. Ahmad R, Mustafa M, Turkyilmazoglu M (2017) Buoyancy effects on nanofluid flow past a convectively heated vertical Riga-plate: a numerical study. Int J Heat Mass Transf 111:827-835. https:// doi.org/10.1016/j.ijheatmasstransfer.2017.04.046

21. Bhatti MM, Abbas T, Rashidi MM (2016) Effects of thermal radiation and electromagnetohydrodynamics on viscous nanofluid through a Riga plate. Multidiscip Model Mater Struct 12(4):605618. https://doi.org/10.1108/MMMS-07-2016-0029

22. Hayat T, Abbas T, Ayub M, Farooq M, Alsaedi A (2016) Flow of nanofluid due to convectively heated Riga plate with variable thickness. J Mol Liq 222:854-862. https://doi.org/10.1016/j.molli q.2016.07.111

23. Ahmed N, Khan U, Mohyud-Din ST (2017) Influence of thermal radiation and viscous dissipation on squeezed flow of water between Riga plates saturated with carbon nanotubes. Colloids Surf A Physicochem Eng Asp 522:389-398. https://doi. org/10.1016/j.colsurfa.2017.02.083

24. Hayat T, Khan M, Imtiaz M, Alsaedi A (2017) Squeezing flow past a Riga plate with chemical reaction and convective conditions. J Mol Liq 225:569-576. https://doi.org/10.1016/j.molli q.2016.11.089

25. Hayat T, Khan M, Khan MI, Alsaedi A, Ayub M (2017) Electromagneto squeezing rotational flow of Carbon (C)-Water kerosene oil nanofluid past a Riga plate: a numerical study. PLoS ONE 12(8):1-17. https://doi.org/10.1371/journal.pone.01809 76

26. Iqbal Z, Mehmood Z, Azhar E, Maraj EN (2017) Numerical investigation of nanofluidic transport of gyrotactic microorganisms submerged in water towards Riga plate. J Mol Liq 234:296-308. https://doi.org/10.1016/j.molliq.2017.03.074

27. Khan SU, Al-Khalid K, Khan MI (2020) Convective nonlinear thermally developed flow of thixotropic nanoliquid configured by Riga surface with gyrotactic microorganism and activation energy: a bio-technology and thermal extrusion model. Int Commun Heat Mass Transf. https://doi.org/10.1016/j.ichea tmasstransfer.2020.104966

28. Iqbal Z, Azhar E, Mehmood Z, Maraj EN (2017) Melting heat transport of nanofluidic problem over a Riga plate with erratic thickness: use of Keller Box scheme. Results Phys 7:3648-3658. https://doi.org/10.1016/j.rinp.2017.09.047

29. Nassem A, Shafiq A, Zhao L, Farooq MU (2018) Analytical investigation of third grade nanofluidic flow over a riga plate using Cattaneo-Chirstov model. Results Phys 9:961-969. https://doi. org/10.1016/j.rinp.2018.01.013

30. Rasool G, Zhang T (2019) Characterictics of chemical reaction and convective boundary conditions in powell-eyring nanofluid flow along a radiative Riga plate. Heliyon. https://doi. org/10.1016/j.heliyon.2019.e01479

31. Daniel YS, Aziz ZA, Ismail Z, Salah F (2018) Impact of thermal radiation on electrical MHD flow of nanofluid over nonlinear stretching sheet with variable thickness. Alexandria Eng J 57(3):2187-2197. https://doi.org/10.1016/j.aej.2017.07.007

32. Shafiq A, Zari I, Khan I, Khan TS, Sheikh AH, Sherif ESM (2020) Marangoni driven boundary layer flow of carbon nanotubes toward a Riga plate. Front Phys. https://doi.org/10.3389/ fphy. 2019.00215

33. Krishnamurthy MR, Gireesha BJ, Prasannakumara BC, Gorla RSR (2016) Thermal radiation and chemical reaction effects on boundary layer slip flow and melting heat transfer of nanofluid induced by a nonlinear stretching sheet. Nonlinear Eng 5(3):147-159. https://doi.org/10.1515/nleng-2016-0013

34. Prasannakumara BC, Shashikumar NS, Ramesh GK (2020) Magnetohydrodynamic flow of dusty fluid over Riga plate with 
deforming isothermal surfaces with convective boundary condition. Songklanakarin J Sci Technol 42(3):487-495

35. Shamshuddin M, Mishra SR, Bég OA, Kadir A (2019) Viscous dissipation and joule heating effects in non-fourier MHD squeezing flow, heat and mass transfer between Riga plates with thermal radiation: variational parameter method solutions. Arab J Sci Eng 44:8053-8066. https://doi.org/10.1007/ s13369-019-04019-x

36. Shamshuddin MD, Satya Narayana PV (2019) Combined effect of viscous dissipation and Joule heating on MHD flow past a Riga plate with Cattaneo-Christov heat flux. Indian J Phys 94:1385-1394. https://doi.org/10.1007/s12648-019-01576-7

37. Nasir NAAM, Ishak A, Pop I (2019) Stagnation point flow and heat transfer past a permeable stretching/shrinking Riga plate with velocity slip and radiation effects. J Zhejiang Univ Sci A 20:290-299. https://doi.org/10.1631/jzus.A1800029

38. Ramesh GK, Roopa GS, Gireesha BJ, Shehzad SA, Abbasi FM (2017) An electro-magneto-hydrodynamic flow Maxwell nanoliquid past a Riga plate: a numerical study. J Braz Soc Mech Sci Eng 39:4547-4554. https://doi.org/10.1007/s4043 0-017-0900-z

39. Pantokratoras A, Magyari E (2008) EMHD free-convection boundary-layer flow from a Riga-plate. J Eng Math 64(3):303315. https://doi.org/10.1007/s10665-008-9259-6

40. Mallawi FOM, Bhuvaneswari M, Sivasankaran S, Eswaramoorthi $S$ (2020) Impact of double-stratification on convective flow of a non-Newtonian liquid in a Riga plate with Cattaneo-Christov double-flux and thermal radiation. Ain Shams Eng J. https://doi. org/10.1016/j.asej.2020.04.010

41. Ahmad A, Asghar S, Afzal S (2016) Flow of nanofluid past a Riga plate. J Magn Magn Mater 402:44-48. https://doi.org/10.1016/j. jmmm.2015.11.043

42. Wakif A, Chamkha A, Animasaun IL, Zaydan M, Waqas H, Sehaqui $R$ (2020) Novel physical insights into the thermodynamic irreversibilities within dissipative EMHD fluid flows past over a moving horizontal riga plate in the coexistence of wall suction and joule heating effects: a comprehensive numerical investigation. Arab J Sci Eng 45:9423-9438. https://doi.org/10.1007/s1336 9-020-04757-3

43. Das S, Tarafdar B, Jana RN, Makinde OD (2018) Influence of rotational buoyancy on magneto-radiation-convection near a rotating vertical plate. Eur J Mech B Fluids. https://doi.org/10.1016/j. euromechflu.2018.09.010

44. Sivaiah S (2013) MHD flow of a rotating fluid past a vertical porous flat plate in the presence of chemical reaction and radiation. J Eng Phys Thermophy 86:1328-1336. https://doi. org/10.1007/s10891-013-0957-1

45. Reddy BP, Rao JA (2011) Radiation and thermal diffusion effects on an unsteady MHD free convection mass-transfer flow past an infinite vertical porous plate with the hall current and a heat source. J Eng Phys Thermophy 84:1369-1378. https://doi. org/10.1007/s10891-011-0607-4

46. Mbeledogu IU, Ogulu A (2007) Heat and mass transfer of an unsteady MHD natural convection flow of a rotating fluid past a vertical porous flat plate in the presence of radiative heat transfer. Int J Heat Mass Transfer 50:1902-1908. https://doi. org/10.1016/j.ijheatmasstransfer.2006.10.016

47. Alam MM, Sattar MA (2000) Unsteady MHD free convection and mass transfer flow in a rotating system with Hall current, viscous dissipation and Joule heating. J Energy Heat Mass Transfer 22:31-39

48. Iva LM, Hasan MS, Paul SK, Mondal RN (2018) MHD free convection heat and mass transfer flow over a vertical porous plate in a rotating system with Hall current, heat source and suction. Adv Appl Math Mech 6(1):49-64

49. Attia HA, Sayed-Ahmedm ME (2004) Hall effect on unsteady MHD Couette flow and heat of a Bingham fluid with suction and injection. Appl Math Model 28:1027-1045. https://doi. org/10.1016/S0307-904X(04)00051-4

50. Jha BK, Isah BY, Uwanta IJ (2015) Unsteady MHD free convective Couette flow between vertical porous plates with thermal radiation. J King Saud Univ Sci 27(4):338-348. https://doi. org/10.1016/j.jksus.2015.06.005

51. Chauhan DS, Khemchandani V (2016) Entrophy generation in the poiseuille flow of a temperature dependent viscosity fluid through a channel with a naturally permeable wall under thermal radiation. Adv Appl Sci Res 7(4):104-120

52. Hassan AR, Maritz R, Gbadeyan JA (2017) A reactive hydromagnetic heat generating fluid flow with thermal radiation within porous channel with symmetrical convective cooling. Int J Therm Sci 122:248-256. https://doi.org/10.1016/j.ijthermals ci.2017.08.022

Publisher's Note Springer Nature remains neutral with regard to jurisdictional claims in published maps and institutional affiliations. 